\title{
THE RELATIONS BETWEEN DIABETES MELLITUS TYPE 2 ON THE INCIDENCE CATARACT IN BALAI KESEHATAN MATA MAKASSAR IN 2016
}

\author{
A.NURUL AMALIAH'AMI FEBRIZA' \\ 1 Student Medical Faculty University of Mubammadiyah Makassar \\ 2 Senior lecturer, Physiology Departement, Medical Faculty University of Muhammadiyah Makassar \\ Correspondence :Ami Febriza. Hp 085256655987, Email: amifebrizaachmad@gmail.com
}

\begin{abstract}
Summary
The aim of this research was to know about the correlation between cataract occurance with Diabetes Mellitus. This research was performed in Medical Record Departement of Balai Kesehatan Mata Masyarakat Makassar using medical record on the period of January 2016 to October 2016 with case control design, consist of 74 subjects which were divided into cataract as case, consist of 37 subjects and without cataract as control, consist of 37 subjects. Data of diabetes mellitus history were collected from patient medical record and analyzed by Chi Square with the significance's degree was $\mathrm{p}<0.05$. The result showed moderate correlation between cataract occurance and diabetes mellitus $(\mathrm{p}=0.002)$ with Odds Ratio (OR) 4,563 (IC : $1,683-12,371)$
\end{abstract}

KEYWORDS : Cataract, Diabetes Melitus

\section{PENDAHULUAN}

Mata adalah salah satu indera yang penting bagi manusia, melalui mata manusia menyerap informasi visual yang digunakan untuk melaksanakan berbagai kegiatan. Namun gangguan terhadap penglihatan banyak terjadi, mulai dari gangguan ringan hingga gangguan yang berat yang dapat mengakibatkan kebutaan. Upaya mencegah dan menanggulangi gangguan penglihatan dan kebutaan perlu mendapatkan perhatian. Katarak merupakan penyebab utama gangguan penglihatan dan kebutaan di Indonesia dan di dunia. Dari semua kebutaan pada masyarakat, lebih dari 50\% disebabkan oleh katarak. Diperkirakan di seluruh dunia terdapat 50 juta penderita kebutaan dan sekitar 20 juta disebabkan oleh katarak. 1,2,3

Hasil Riset Kesehatan Dasar tahun 2013, prevalensi katarak semua umur tahun 2013 adalah 1,8 persen. Prevalensi katarak tertinggi di Sulawesi
Utara (3,7\%) diikuti oleh Jambi (2,8\%) dan Bali (2,7\%) Sulsel 2,5\%. Prevalensi katarak terendah ditemukan di DKI Jakarta (0,9\%) diikuti Sulawesi Barat $(1,1 \%) .{ }^{4}$

Katarak adalah setiap kekeruhan pada lensa. Penuaan merupakan penyebab katarak terbanyak, tetapi banyak juga faktor lain yang mungkin terlibat, antara lain : trauma, toksin, penyakit sistemik (mis.,diabetes), merokok, dan herediter. ${ }^{5}$

Pada penderita Diabetes Mellitus diketahui adanya peningkatan angka kejadian katarak. Benson (1998) menyatakan bahwa penderita Diabetes Mellitus mempunyai kecenderungan menderita katarak 25 kali lebih tinggi dibanding yang tidak menderita Diabetes Mellitus. Aiello (2000) mengungkapkan bahwa $40 \%$ penderita Diabetes Mellitus menderita 
The Relations Between Diabetes Mellitus Type 2 On The Incidence

Cataract In Balai Kesehatan Mata Makassar In 2016

katarak Diabetes. Komplikasi pada mata terjadi sekitar 20 tahun setelah onset sekalipun diabetesnya tampak cukup terkontrol. Kadar gula darah yang tinggi dapat menyebabkan berbagai macam komplikasi diabetes, termasuk katarak diabetes. Berdasarkan data kepustakaan, kadar gula darah tinggi meningkatkan resiko berkembangnya katarak. 3,4 ,

Menurut WHO, diperkirakan terdapat 422 juta orang dewasa yang hidup dengan diabetes pada tahun 2014, dibandingkan pada tahun 1980 terdapat 180 juta jiwa. Prevalensi ini naik dua kali lipat sejak tahun 1980, naik dari 4,7\% menjadi 8,5\%. Diabetes menyebabkan 1,5 juta kematian pada tahun 2012. Glukosa darah yang lebih tinggi dari optimal menyebabkan peningkatan jumlah masyarakat yang meninggal yaitu 2,2 juta seiring dengan meningkatnya risiko penyakit kardiovaskuler dan lainnya. ${ }^{6}$

Secara epidemiologi, diperkirakan bahwa pada tahun 2030 prevalensi Diabetes Melitus (DM) di Indonesia mencapai 21,3 juta orang . Hasil dari Riset Kesehatan Dasar (Riskesdas) tahun 2013, proporsi penduduk $\geq 15$ tahun dengan DM sebesar 6,9\%. Prevalensi penderita DM berdasarkan wawancara (pernah didiagnosa dan ada gejala) mengalami peningkatan dari 1,1\% pada tahun 2007 menjadi 2,4\% pada tahun 2013. Prevalensi DM yang terdiagnosa dan atau ada gejala, tertinggi di Sulawesi Tengah (3,7\%), Sulawesi Utara (3,6\%), dan Sulawesi Selatan $(3,4 \%)$. Sedangkan proporsi penduduk umur $\geq 15$ tahun dengan Toleransi Glukosa Terganggu (TGT) mencapai 29,9\%. Hal ini berarti akan semakin banyak penduduk yang berisiko tinggi untuk menderita DM. Hasil Riset Kesehatan Dasar (Riskesdas) tahun 2013, diperoleh prevalensi diabetes melitus berdasarkan diagnosis dokter dan gejala meningkat sesuai dengan bertambahnya umur, namun mulai umur $\geq 65$ tahun cenderung menurun. Prevalensi DM cenderung lebih tinggi pada masyarakat dengan tingkat pendidikan tinggi dan dengan kuintil indeks kepemilikan tinggi. ${ }^{4}$

Sebagian besar (78\%) pemecahan glukosa didalam lensa melalui jalur glikolisis anaerobik, 14\% melalui jalur pentosa fosfat, sekitar 5\% melalui jalur poliol. Pada kondisi hiperglikemia, jalur glikolisis anaerobik cepat jenuh, dan glukosa akan memilih jalur poliol. Pada jalur poliol glukosa dirubah menjadi sorbitol. Pada keadaan dimana sorbitol dipecah menjadi fruktosa oleh enzym Polyol Dehydrogenase, namun pada Diabetes Mellitus kadar enzym Polyol Dehydrogenase rendah sehingga sorbitol menumpuk di dalam lensa mata. Keadaan kondisi hipertonik akan menarik masuk cairan akuos ke dalam lensa mata, merusak arsitektur lensa dan terjadi kekeruhan lensa. Teori klasik mekanisme terjadinya katarak Diabetes yang sampai saat masih dianut adalah teori osmotik katarak. 8

Wisconsin Epidemiologic Study of Diabetic Retinopathy juga telah melakukan penelitian mengenai katarak dan menemukan insiden katarak pada penderita diabetes melitus. Studi kohort oleh Beaver Dam Eye Study juga menemukan adanya hubungan antara diabetes melitus dengan pembentukan katarak pada pasien dewasa. Studi 
ini menyatakan bahwa insiden dan perjalanan penyakit katarak posterior subkapsular dan kortikal berhubungan dengan diabetes. ${ }^{8}$

Berdasarkan beberapa penelitian diatas, maka penulis ingin meneliti kejadian katarak sebagai akibat komplikasi dari penyakit diabetes melitus di Balai Kesehatan Mata Makassar

\section{METODE PENELITIAN}

Penelitian ini merupakan penelitian deskriptif analitik dengan pendekatan case control. Subjek penelitiain yang diambil adalah pasien katarak yang berobat ke BKMM Makassar. Pengumpulan data menggunakan data sekunder dari rekam medik pasien. Dalam penelitian ini, pasien dibagi dalam dua kelompok yakni pasien katarak sebagai kelompok kasus dan pasien penyakit mata non katarak sebagai kelompok kontrol. Pasien yang berobat dilihat apakah menderita diabetes melitus atau tidak.

Populasi dalam penelitian ini adalah semua pasien kasus baru pada Januari-Oktober 2016 sebanyak 10950 populasi. Dengan jumlah sampel sebanyak 74 sampel, yang dibagi menjadi 37 kelompok kasus dan 37 kelompok kontrol.

Teknik sampling yang digunakan yaitu, nonprobability sampling, consecutive sampling, dimana semua subjek yang datang secara berurutan dan memenuhi kriteria pemilihan dimasukkan dalam penelitian sampai jumlah subyek yang diperlukan terpenuhi.

Adapun kriteria inklusi dan ekslusi, baik dari kelompok kasus dan kelompok kontrol sebagai berikut :

\section{Kriteria Kasus}

Kriteria inklusi untuk kasus adalah pasien yang terdaftar namanya dalam rekam medik dan didiagnosis sebagai katarak di BBKMM Makassar. Sementara kriteria eksklusi untuk kasus adalah pasien yang rekam medik tidak lengkap.

2. Kriteria Kontrol

Kriteria inklusi untuk kontrol adalah pasien yang tercantum namanya dalam rekam medik yang didiagnosis sebagai penyakit mata non katarak di BBKMM Makassar. Sementara itu kriteria eksklusi untuk control adalah pasien yang memiliki rekam medik tidak lengkap.

\section{HASIL PENELITIAN}

Berdasarkan tabel 5.1 di dapatkan bahwa frekwensi perempuan lebih besar pada kelompok katarak $(62,2 \%)$ atau 23 orang dan bukan Katarak $(54,1 \%)$ atau 20 orang, di bandingkan dengan frekwensi laki laki, baik pada kelompok katarak $(37,8 \%)$ atau 14 orang dan bukan katarak $(45,9 \%)$ atau 17 orang.

Berdasarkan tabel 5.2 menunjukkan bahwa pasien Katarak yang berobat di BKMM baik laki-laki maupun perempuan terbanyak berturut-turut berada pada kelompok usia 45-<55 tahun $(54,1 \%)$ atau 20 orang, kelompok usia $>55$ tahun $(24,3 \%)$ atau 9 orang, dan kelompok usia $35-<45$ tahun $(21,6 \%)$ atau 8 orang.

Sementara itu, untuk pasien Bukan Katarak yang berobat di BKMM baik laki-laki maupun perempuan terbanyak berturut-turut 
berada $45-<55$ tahun $(43,2 \%)$ atau 16 orang, kelompok usia 35-<45 tahun $(32,4 \%)$ atau 12 orang, dan kelompok usia $>55$ tahun $(24,3 \%)$ atau 9 orang.

Tabel 5.1 Distribusi Frekuensi Jenis Kelamin Pasien Katarak dan Bukan Katarak di BKMM Makassar Tahun 2016

\begin{tabular}{|c|c|c|c|c|}
\hline \multirow{2}{*}{$\begin{array}{c}\text { Jenis } \\
\text { Kelamin }\end{array}$} & \multicolumn{2}{|c|}{ KATARAK } & \multicolumn{2}{c|}{$\begin{array}{c}\text { BUKAN } \\
\text { KATARAK }\end{array}$} \\
\cline { 2 - 5 } & $\mathbf{N}$ & $\%$ & $\mathbf{N}$ & $\%$ \\
\hline Laki - Laki & 14 & 37,8 & 17 & 45,9 \\
\hline Perempuan & 23 & 62,2 & 20 & 54,1 \\
\hline Jumlah & 37 & 100 & 37 & 100 \\
\hline
\end{tabular}

Sumber: Data Rekam Medik Balai Kesehatan Mata Masyarakat (BKMM) Makassar Tahun 2016

Tabel 5.2 Distribusi Frekuensi Usia Pasien Katarak dan Bukan Katarak di BKMM Makassar Tahun 2016

\begin{tabular}{|c|c|c|c|c|}
\hline \multirow{2}{*}{ Umur } & $\mathbf{2}$ & $\%$ & \multicolumn{2}{c|}{ BUKAN KATARAK } \\
\cline { 2 - 5 } & $\mathbf{N}$ & 21,6 & 12 & $\%$ \\
\hline $\mathbf{3 5}-<\mathbf{4 5}$ & 8 & 54,1 & 16 & 43,2 \\
\hline $\mathbf{4 5}-\mathbf{5 5 5}$ & 20 & 24,3 & 9 & 24,3 \\
\hline$\geq \mathbf{5 5}$ & 9 & 100 & 37 & 100 \\
\hline Jumlah & 37 & & & \\
\hline
\end{tabular}

Sumber: Data Rekam Medik Balai Kesehatan Mata Masyarakat (BKMM) Makassar Tahun 2016

Tabel 5.3 Hubungan antara Diabetes Melitus Terhadap Kejadian Katarak di BBKMM Makassar Tahun 2016

\begin{tabular}{|c|c|c|c|c|c|c|c|}
\hline \multirow{2}{*}{ DM } & \multicolumn{2}{|c|}{ Katarak } & \multicolumn{2}{|c|}{ Non Katarak } & \multirow{2}{*}{$\begin{array}{c}\text { Jumlah } \\
\mathrm{N}\end{array}$} & \multirow[t]{2}{*}{ p-Value } & \multirow{2}{*}{$\begin{array}{c}\text { OR }(95 \% \\
\text { CI) }\end{array}$} \\
\hline & $\mathrm{N}$ & $\%$ & $\mathrm{~N}$ & $\%$ & & & \\
\hline DM & 25 & 67,6 & 9 & 24,4 & 34 & \multirow{3}{*}{0,002} & 4,563 \\
\hline $\begin{array}{c}\text { Bukan } \\
\text { DM }\end{array}$ & 12 & 32,4 & 28 & 75,6 & 40 & & $\begin{array}{l}(1,683- \\
12,371)\end{array}$ \\
\hline Jumlah & 37 & 100 & 37 & 100 & 74 & & \\
\hline
\end{tabular}

Sumber: Data Rekam Medik Balai Kesehatan Mata Masyarakat (BKMM) Makassar Tahun 2016

Berdasarkan tabel 5.3 hasil penelitian di BKMM Makassar tentang hubungan diabetes melitus terhadap kejadian didapatkan $67,6 \%$ pasien katarak (25 orang dari 37 orang subyek penelitian) yang memiliki riwayat diabetes melitus dan sekitar $32,4 \%$ pasien katarak (12 orang dari 35 orang subyek penelitian) yang tidak memiliki riwayat diabetes melitus. Selanjutnya $24,3 \%$ pasien tanpa 
katarak (9 orang dari 37 orang subyek penelitian) yang memiliki riwayat diabetes melitus dan sekitar $75,5 \%$ pasien tanpa katarak (28 orang dari 37 orang subyek penelitian) yang tidak memiliki riwayat diabetes melitus.

Analisis data dalam penelitian ini dilakukan uji Chis Square, dengan hasil uji statistik diperoleh nilai p 0,002 ( $<<0,05)$ maka hipotesis nol ditolak dan hipotesis alternatif diterima. Hal ini berarti ada hubungan antara diabetes melitus terhadap kejadian katarak di Balai Besar Kesehatan Mata Masyarakat (BBKMM) Makassar tahun 2016.

Untuk mengetahui besar risiko kejadian katarak pada pasien dengan riwayat DM maka diketahui OR $(95 \% \mathrm{CI})=4,563(1,683-12,371)$. Hal ini berarti penderita diabetes melitus mempunyai risiko 4 kali untuk terjadinya katarak dibandingkan dengan pasien yang tidak memiliki riwayat DM.

\section{PEMBAHASAN}

Menurut beberapa penelitian, jalur poliol dikatakan memainkan peran dalam perkembangan katarak pada pasien diabetes. Enzim aldose reduktase (AR) yang terdapat dalam lensa mengkatalisis reduksi glukosa menjadi sorbitol melalui jalur poliol. Akumulasi sorbitol intrasel menyebabkan perubahan osmotik sehingga mengakibatkan serat lensa hidropik yang degenerasi dan menghasilkan gula katarak. Dalam lensa, sorbitol diproduksi lebih cepat daripada diubah menjadi fruktosa oleh enzim sorbitol dehydrogenase (SD), dan sifat sorbitol yang sukar keluar dari lensa melalui proses difusi menyebabkan peningkatan akumulasi sorbitol. Ini menciptakan efek hiperosmotik yang nantinya menyebabkan infus cairan untuk menyeimbangkan gradien osmotik. Keadaan ini menyebabkan keruntuhan dan pencairan serat lensa yang akhirnya membentuk kekeruhan pada lensa. Selain itu, stres osmotik pada lensa yang disebabkan oleh akumulasi sorbitol menginduksi apoptosis pada sel epitel lensa yang mengarah ke pengembangan katarak. ${ }^{8}$

Hasil uji statistik menggunakan uji Chis Square, diperoleh nilai p 0,002 $(\mathrm{p}<0,05)$ yang berarti ada hubungan antara diabetes melitus tipe 2 terhadap kejadian katarak di Balai Besar Kesehatan Mata Masyarakat (BBKMM) Makassar tahun 2016. Dengan OR $(95 \% \mathrm{CI})=4,563(1,683-12,371)$. $\mathrm{Hal}$ ini berarti penderita diabetes melitus tipe 2 mempunyai risiko 4 kali untuk terjadinya katarak dibandingkan dengan pasien yang tidak memiliki riwayat DM.

Hal ini juga sesuai dengan penelitian yang dilakukan oleh Rizkawati dkk, yang dilakukan di RSUD DR. SOEDARSO PONTIANAK. Pada penelitian ini, hasil perhitungan statistik uji Korelasi Lambda didapatkan nilai $\mathrm{p}=0,033$, dimana $\mathrm{p}<0,05$, yang menunjukkan bahwa diabetes melitus mempunyai korelasi yang signifikan dalam terjadinya katarak. Selain itu, nilai Odds Rasio (OR) didapatkan 7,125 (>1) yang berarti bahwa penderita diabetes melitus berisiko tujuh kali lebih besar untuk menderita katarak dibanding penderita non-diabetes melitus. ${ }^{15}$

Berdasarkan data yang diambil dari rekam medik BKMM didapatkan bahwa penderita katarak dengan jenis kelamin perempuan (23 
The Relations Between Diabetes Mellitus Type 2 On The Incidence

Cataract In Balai Kesehatan Mata Makassar In 2016

orang) lebih banyak di bandingkan dengan laki-laki (14 orang), hampir dua kali lipatnya. Hal ini relevan dengan hasil penelitian Mvitu Muaka, Longo Mbenza dan Nkondi Mbadi A Nsungu dari Departemen Oftalmologi, Universitas Kinshasa, Congo, Afrika menyatakan bahwa insiden dan prevalensi katarak diabetik lebih tinggi 2 kali lipat pada pasien perempuan di banding dengan pasien laki-laki $(\mathrm{OR}=2,02) \cdot{ }^{16}$

Kemudian dari segi Usia, pasien katarak terbanyak berada pada kelompok usia $45-<55$ tahun dan juga di atas 55 tahun, hal ini sesuai dengan penelitian yang dilalukan oleh Rijal Rasyid $\mathrm{dkk}$, yang melakukan penelitian di tempat yang sama, yaitu BKMM pada tahun 2010 menunjukkan Hasil analisis statistik dengan menggunakan Uji Chi Square diperoleh nilai $\mathrm{p}=$ 0,000 dengan $\alpha=(\mathrm{p}<0,05)$, dengan demikian maka dapat disimpulkan bahwa terdapat hubungan yang bermakna antara usia dengan kejadian katarak. ${ }^{17}$

Hal ini sejalan dengan beberapa studi klinik telah menunjukkan bahwa perkembangan katarak terjadi lebih sering dan lebih awal pada penderita diabetes melitus dibanding penderita yang non-diabetes. Meningkatnya jumlah penderita diabetes melitus di dunia baik tipe 1 maupun tipe 2 menyebabkan tingginya insiden katarak diabetik. Data dari beberapa studi mengenai mata menunjukkan peningkatan prevalensi katarak sebesar tiga sampai empat kali lipat pada penderita diabetes melitus yang berusia di bawah 65 tahun dan peningkatan sebesar dua kali lipat lebih pada penderita diabetes melitus yang berusia di atas 65 tahun. Risiko untuk mengalami katarak semakin meningkat pada pasien yang telah lama mengalami diabetes melitus dan dengan kontrol gula darah yang kurang baik. ${ }^{8}$ Hasil penelitian dari Beaver Dam Eye Study menunjukkan adanya hubungan antara diabetes melitus dengan katarak. Studi ini juga menyatakan peningkatan kadar hemoglobin terglikosilasi berhubungan dengan meningkatnya resiko untuk mengalami katarak nuklear dan kortikal. Penelitian lebih jauh dari studi ini menunjukkan bahwa semakin lama seseorang menderita diabetes melitus maka semakin tinggi resikonya untuk mengalami katarak kortikal yang diikuti dengan semakin tingginya resiko orang tersebut untuk menjalani operasi katarak. ${ }^{8}$

Walaupun dari penelitian ini tidak dapat ditentukan lamanya seseorang menderita diabetes melitus, tetapi hasil penelitian ini telah menunjukkan bahwa diabetes melitus memang dapat meningkatkan risiko terjadinya katarak sebagai efek akumulasi dari keadan hiperglikemi. Seperti yang telah diketahui, diabetes melitus adalah suatu kelainan yang sulit penatalaksanaannya karena merupakan suatu penyakit kronik yang akan diderita seumur hidup yang progresifitas penyakitnya akan terus berjalan dan pada suatu saat dapat menimbulkan komplikasi. Kondisi ini akan menyebabkan masalah di berbagai aspek kehidupan. Karena itu, deteksi dini terhadap diabetes melitus sangat penting dilakukan agar dapat dilakukan pengontrolan terhadap gula darah sedini mungkin 10 sehingga dapat terhindar dari komplikasi yang 
berbahaya dan tidak diinginkan yang salah satunya adalah katarak $^{8}$. Adapun keterbatasan dalam melakukan penelitian ini adalah karena sampel yang digunakan hanya merupakan sampel dengan jumlah minimal sehingga tingkat kepercayaannya kurang. Selain itu, terdapat beberapa kendala dalam mengambil data rekam medik, hal ini dikarenakan BKMM masih menulis rekam medik secara konvensional.

\section{KESIMPULAN}

Berdasarkan hasil penelitian, dapat disimpulkan beberapa hal berikut: (1) Frekuensi jumlah penderita katarak dengan riwayat diabetes melitus tipe 2 adalah sebesar 25 orang $(67,6 \%)$. (2) Frekuensi jumlah penderita katarak tanpa riwayat diabetes melitus tipe 2 adalah sebesar 12 orang (32,4\%). (3) Hasil penelitian menunjukkan bahwa terdapat hubungan antarar iwayat penyakit diabetes melitus tipe 2 dengan terjadinya penyakit katarak di BKMM Makassar tahun 2016 dimana penderita diabetes melitus berisiko empatkali lebih besar untuk menderita katarak dibanding penderita non-diabetes melitus. Sehingga Ha diterima dan Ho ditolak dengan nilai $p=0,002$. (4) Allah SWT melarang perilaku Israf. Sebagaimana firman Allah dalam Surat Al-A'raf ayat 31 yang melarang perilaku berlebih-lebihan, khususnya dalam hal makan dan minum. "Makanlah untuk hidup, jangan hidup untuk makan".

Saran yang dapat diberikan bagi peneliti selanjutnya adalah disarankan penelitian selanjutnya berupa penelitian kohort agar analisis korelasinya menjadi lebih kuat. Sementara bagi masyarakat untuk lebih meningkatkan pemahaman terhadap penyakit degenerative yang menyangkut kesehatan indera penglihatan. Dianjurkan kepada penderita Diabetes Mellitus untuk teratur mengontrol kadar Gula Darah Sewaktu (GDS) Serta bagi Institusi Kesehatan adalah dengan menyusun program pencegahan/ penanggulangan penyakit katarak yang dapat dilakukan melalui penyuluhan atau seminar kesehatan tentang upaya preventif/ pencegahan katarak di Provinsi Sulawesi Selatan

\section{DAFTAR PUSTAKA}

1. InfoDATIN. Situasi Gangguan Penglihatan dan Kebutaan. 2014.

2. Kemenkes RI. Katarak sebabkan 50\% kebutaan. 2016;1-2.

3. Lukitasari A. Katarak Diabetes. 2011;42-7.

4. Badan Penelitian dan Pengembangan Kesehatan. Riset Kesehatan Dasar (RISKESDAS) 2013. Lap Nas 2013. 2013;1-384.

5. Riordan P, Whitcher P. Vaughan dan Asbury Oftalmologi Umum. Edisi 17. Jakarta : Penerbit Buku Kedokteran EGC. 2010. 169: 175:319 p.

6. World Health Organization. Global Report on Diabetes. France: World Health Organization. 2016

8. Pollreisz A, Schmidt-Erfurth U. Diabetic cataract-pathogenesis, epidemiology and treatment. J Ophthalmol [Internet]. 2010;2010:608751. Available from: https://www.researchgate.net/publication/ 45200506_Diabetic_Cataract-

Pathogenesis_Epidemiology_and_Treatme nt

9. Purnamasari, Dyah. Diagnosis dan Klasifikasi Diabetes Melitus Buku Ajar Ilmu Penyakit Dalam . Jilid II. Edisi 6. Jakarta: Pusat Penerbitan Department Ilmu Penyakit 
Dalam FKUI. 2014. 2315 p.

10. Rudianto AD. Konsensus Pengelolaan dan Pencegahan Diabetes Melitus Tipe 2 di Indonesia 2011. 2011. 1-58 p.

11. Schteingart, David E. Pankreas: Metabolisme Glukosa dan Diabetes Melitus Patofisiologi Konsep Klinis Proses-Proses Penyakit Volume 2. Edisi 6. Jakarta : Penerbit Buku Kedokteran EGC. 2013. 1261 p.

12. K.Kendall, L.Tao. Sinopsis Organ System Endokrinologi. Tangerang Selatan : KARISMA Publishing Group. 2013. 165 p.

13. Ilyas S. Ilmu Penyakit Mata . Edisi Kelima. Fakultas Kedokteran Universitas Indonesia, Jakarta. 2015. 210-12:214-16 p.

14. Patel PM, Jivani N, Malaviya S, Gohil T, Bhalodia Y. Cataract: A major secondary diabetic complication. Int Curr Pharm J
[Internet]. 2012;1(7):180-5. Available from: http://www.banglajol.info/index.php/ICPJ /article/view/10813

15. Rizkawati. Hubungan Antara Kejadian Katarak Dengan Diabetes Melitus Di Polimata RSUD Soedarso Pontianak. Naskapublikasi. 2012;

16. J NMAN. Diabetes \& Metabolism Relationship between Cataract and Metabolic Syndrome among African Type 2 Diabetics. 2011;2(9)

17. Rasyid Rijal. Faktor Yang Berhubungan Dengan Kejadian Katarak Di Balai Kesehatan Mata Masyarakat Makassar (BKMM). 2010 